\title{
Produção e caracterização de biofilmes de fécula de mandioca com extratos aquoso e alcoólico de própolis
}

\section{Cristieli Nunes da Silva, Talita Moura Fukuoka e Maria Raquel Manhani*}

Instituto Federal de Educação, Ciência e Tecnologia de São Paulo. Campus Suzano. Av. Mogi das Cruzes, 1501. Parque Suzano. Suzano-SP, Brasil (CEP 08673-010). *E-mail: raquelmanhani@ifsp.edu.br.

Resumo. Os polímeros sintéticos são amplamente utilizados nas indústrias devido à variedade de aplicações que possuem e por apresentarem longa durabilidade. Contudo, a grande resistência desses materiais contribui diretamente para que demorem centenas de anos para serem degradados, o que tem causado inúmeros problemas ambientais. A partir desse cenário, muitas empresas que consumiam polímeros em grande quantidade, iniciaram uma busca por alternativas para tratamento desses resíduos ou por substitutos para os materiais que utilizavam, e nessa nova tendência, alguns produtos se destacaram, como por exemplo, os biopolímeros, produzidos a partir de matériasprimas de fontes renováveis, dentre as quais, destacam-se o amido de milho, de mandioca e de batata, polilactato e poliidroxialcanoato. Neste trabalho, biofilmes de fécula de mandioca foram preparados pela técnica de casting, utilizando-se glicerol como plastificante, e incorporados de extratos etanólico e aquoso de própolis (EGP e EAP, respectivamente) em três diferentes concentrações $(1,2 \%, 1,5 \%$ e $1,8 \%)$, a fim de se determinar as propriedades físicas e mecânicas, investigar o tempo de sua biodegradabilidade, além de avaliar possível atividade antibacteriana destes filmes. A avaliação das características físicas e mecânicas demonstrou que os filmes produzidos apresentaram resultados satisfatórios em comparação aos parâmetros encontrados na literatura e em relação à amostra controle (sem extrato). Para algumas das análises, como por exemplo, a umidade e a resistência ao rasgo, pode-se notar que a variação no tipo dos extratos influenciou diretamente os valores obtidos nos ensaios e, consequentemente, o desempenho do material. Quanto à biodegradabilidade, foram alcançados resultados muito favoráveis, visto que após 45 dias, houve a degradação completa dos filmes enterrados em solo arenoso. A respeito da atividade antibacteriana, notou-se a capacidade que ambos os extratos tiveram em inibir as suspensões bacterianas de Escherichia coli e Staphylococcus aureus. Diante do exposto, percebe-se o potencial de utilização

Recebido 25/09/2020

Aceito

30/08/2021

Publicado

31/08/2021

Acesso aberto

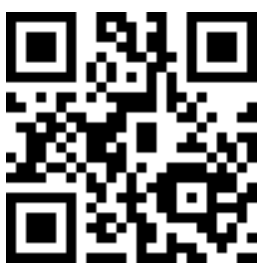

ORCID

(D) 0000-0002-6523-1366 Cristieli Nunes da Silva

(D) 0000-0001-7037-6749 Talita Moura Fukuoka

D 0000-0003-0317-579X Maria Raquel Manhani

ISSN 2359-1412/RBGAS-2020-0144/2020/8/19/41/1257

Rev. Bras. Gest. Amb. Sustent.

http://revista.ecogestaobrasil.net 
dos biofilmes desenvolvidos como alternativa ao uso dos polímeros sintéticos, contribuindo assim para diminuir os impactos negativos causados ao meio ambiente, como alternativa ao uso dos polímeros sintéticos, contribuindo assim para diminuir os impactos causados no meio ambiente.

Palavras-chave: Biopolímero; Mandioca; Própolis; Biodegradabilidade.

Abstract. Production and characterization of cassava biofilms with aqueous and alcoholic propolis extracts. Synthetic polymers are widely used in industries due to the variety of applications they have and their long durability. However, the great resistance of these materials directly contributes to the fact that they take hundreds of years to be degraded, which has caused numerous environmental problems. From this scenario, many companies that consumed polymers in large quantities, started a search for alternatives to treat these residues or substitutes for the materials they used, and in this new trend, some products stood out, such as, for example, biopolymers, produced from raw materials from renewable sources, among which, corn, cassava and potato starch, polylactate and polyhydroxyalkanoate stand out. In this work, cassava starch biofilms were prepared by the casting technique, using glycerol as a plasticizer, and incorporated with ethanol and aqueous propolis extracts (EGP and EAP, respectively) in three different concentrations $(1.2 \%, 1.5 \%$ and $1.8 \%)$, in order to determine the physical and mechanical properties, investigate the time of its biodegradability, in addition to assessing possible antibacterial activity of these films. The evaluation of the physical and mechanical characteristics demonstrated that the films produced presented satisfactory results in comparison to the parameters found in the literature and in relation to the control sample (without extract). For some of the parameters, such as moisture and tear resistance, it can be noted that the variation in the type of extracts directly influenced the values obtained in the tests and, consequently, the performance of the material. As for biodegradability, very favorable results were achieved, since after 45 days, there was complete degradation of the films buried in sandy soil. Regarding the antibacterial activity, the ability of both extracts to inhibit the bacterial suspensions of Escherichia coli and Staphylococcus aureus was noted. Given the above, the potential for using developed biofilms as an alternative to the use of synthetic polymers is perceived, thus contributing to reduce the negative impacts caused on the environment.

Keywords: Biopolymer; Cassava; Propolis; Biodegradability. 


\section{Introdução}

O maior desenvolvimento da química dos polímeros veio com o fim da Segunda Guerra Mundial, quando novas tecnologias possibilitaram a produção desses materiais em grande escala, substituindo facilmente materiais como o aço, vidros e madeiras, usados no cotidiano, principalmente por serem mais leves, duráveis, baratos e com resistência à degradação (Schlemmer, 2007).

Os polímeros sintéticos têm como principais características o baixo custo, fácil processamento, grande variedade de aplicação e durabilidade, sendo que essa última torna sua utilização desvantajosa, pois estes são praticamente inertes à ação de microrganismos, dificultando sua decomposição e resultando em sérios problemas ambientais, devido à grande quantidade de lixo plástico descartado no meio ambiente (Larotonda, 2002).

Schlemmer (2007) afirma que com o aumento da conscientização ecológica, a alta resistência e a lenta deterioração dos polímeros passaram a ser vistas como problemas. Segundo Larotonda (2002), nas últimas décadas, uma solução para a diminuição do descarte desses polímeros no meio ambiente tem sido a reciclagem, porém ela se restringe a alguns segmentos, como por exemplo: usados para fabricação de sacos de lixo, devido a sua qualidade inferior, o que impede o seu uso principalmente nas indústrias alimentícias, umas das principais consumidoras de polímeros, devido à possibilidade de contaminação. Como alternativa de solução para esse problema, surgem os biopolímeros, materiais que se degradam completamente quando expostos a microrganismos no meio ambiente, e vêm ganhando espaço no mercado nas últimas décadas e sendo motivo de várias pesquisas, pelo fato de que os plásticos comuns, em sua grande maioria não apresentam alta biodegradabilidade, contribuindo assim com o acúmulo excessivo de lixo plástico, que levará de dezenas a centenas de anos para ser novamente integrado à natureza (Brito et al., 2011).

Segundo Garcia (2016), o crescimento no mercado mundial de polímeros biodegradáveis é constante, sendo que em 1950 sua utilização era de 5 milhões de toneladas e em 2011 chegou em torno de 100 milhões de toneladas, e aproximadamente $42 \%$ do total foram consumidos no setor de embalagens.

Biopolímeros é a denominação atribuída a polímeros produzidos a partir de matérias-primas obtidas de fontes renováveis. No Brasil, os mais comuns são oriundos de fontes como o amido (obtidos do milho, mandioca, batata e outros), polilactatos (produzidos a partir de ácido láctico liberado por bactérias) e poliidroxialcanoato (produzido por bactérias que metabolizam o milho, óleo vegetal e cana-de-açúcar). Estes podem ser considerados resíduos compostáveis, pois são degradados biologicamente, produzindo $\mathrm{H}_{2} \mathrm{O}, \mathrm{CO}_{2}$ e biomassa, a qual serve como adubo natural, pois não libera nenhum agente nocivo ao meio ambiente, similar à decomposição de outros materiais orgânicos (Silva et al., 2017).

0 amido é a principal fonte de reserva de energia encontrada nas plantas fotossintetizantes, e está presente principalmente em cereais, legumes e tubérculos (Da Róz, 2004), e o que diferencia a composição do amido de fontes diversas são suas propriedades químicas, cuja estrutura é formada por dois tipos de polímeros, a amilose, que compõe de $20 \%$ a $30 \%$ em peso do grânulo de amido e amilopectina, o restante (Larotonda, 2002).

0 amido é encontrado em abundância na natureza, tem caráter renovável, além de custo relativamente baixo, o que o torna alvo de grande interesse para exploração econômica na produção de materiais biodegradáveis (Larotonda, 2002).

A mandioca Manihot esculenta Crant pertence à Família Euphorbiaceae, tem como centro de origem o Brasil e é considerada como um dos principais produtos alimentares, 
cuja produção mundial é de aproximadamente 140 milhões de toneladas (Silva et al., 2008).

De raízes tuberosas, rica em amido, a mandioca in natura tem aproximadamente $70 \%$ de água e $30 \%$ de amido, que é extraído por meio de uma sequência de processos, que resulta em um material branco, fino, inodoro e insípido (Alves et al., 2012).

Segundo Petrikoski (2003), um dos produtos mais importantes obtidos a partir da mandioca é a fécula, conhecido também por polvilho doce ou goma, definido como um carboidrato que é extraído de suas raízes. Conforme a literatura, o que difere o amido da fécula é o fato de que a fécula é obtida de matérias-primas subterrâneas, enquanto o amido pode ser obtido de qualquer parte da planta, porém sua estrutura química é a mesma.

Empregado em diversos segmentos da indústria, e por ser um material com ótima biodegradabilidade, o amido de mandioca torna-se um investimento muito atrativo, principalmente porque encontramos uma grande escala de cultivo de mandioca no país (Ferreira e Bento, 2013) e tem sido utilizado principalmente na elaboração de filmes que substituem embalagens não degradáveis e não renováveis em indústrias de alimentos devido a suas características atrativas como incolor, inodoro, insípido e atóxico (Cunha, 2017).

No Brasil, em 2017, segundo o IBGE (Janeiro 2018) a média de produtividade de mandioca atingiu o equivalente a 20,6 milhões de toneladas, com um rendimento médio de $14.642 \mathrm{~kg} / \mathrm{ha}$.

Ferreira e Bento (2013) relatam que a técnica de casting consiste na secagem de uma solução formadora de filme sobre uma superfície. A obtenção de filme a partir desta técnica dá-se por meio da solubilização do amido em um solvente, normalmente água, que em seguida é exposto ao aquecimento, resultando na gelatinização; nessa etapa, os componentes do amido (amilose e amilopectina) sofrem dispersão na água, formando uma solução filmogênica. Esta solução é colocada em um suporte, exposta a um processo de secagem onde os componentes do amido se reorganizam de forma a gerar uma matriz contínua que dá origem ao filme.

A própolis é uma resina produzida pelas abelhas, cuja matéria prima é coletada em diferentes partes das plantas, que misturadas com secreções liberadas pelo seu organismo, produzem um material de coloração e consistência variadas, usado como proteção das colmeias contra invasão de microrganismos e insetos, para fechar pequenas frestas e embalsamar insetos mortos no interior da colmeia. Sua coloração pode variar de acordo com a região, origem da planta e época de extração, podendo oscilar de uma tonalidade marrom escuro até um tom mais avermelhado (Araújo, 2014). Tem aspecto pegajoso, o que inviabiliza sua utilização em sua forma bruta. Assim, muitas vezes é purificada por extração com solventes que preservam os compostos fenólicos, garantindo sua atividade biológica (Cunha, 2017).

Segundo Cunha (2017), a própolis é composta por 50\% de resina, 30\% de cera, 5\% de pólen, $10 \%$ de óleos aromáticos e $5 \%$ de outros resíduos orgânicos, porém esses valores podem variar de acordo com a matéria-prima usada pelas abelhas.

Quanto às características físicas e químicas, a própolis brasileira é classificada em 12 grupos, distinguíveis pelas cores e regiões onde é encontrada. Um novo grupo tem sido classificado na região nordeste do país, como fonte promissora de compostos bioativos. No Brasil, sua coleta é realizada o ano todo, podendo haver variações sazonais, porém não são significativas, pois não afetam a qualidade do composto ativo, influenciando apenas na quantidade produzida (Cunha, 2017).

Os principais compostos químicos encontrados na própolis são classificados como: ácidos e ésteres alifáticos, ácidos e ésteres aromáticos, açúcares, álcoois, aldeídos, ácidos graxos, aminoácidos, esteroides, cetonas, charconas e di-hidrocharconas, flavonoides, terpenoides, proteínas, vitaminas B1, B2, B6, C e E, bem como diversos minerais, sendo que os flavonoides têm sido alvo de interesses científico e terapêutico, pois atuam como 
antioxidantes e apresentam atividades antimicrobiana e moduladora do sistema imune (Araújo, 2014), além de possuir propriedades antisséptica, anestésica, antiespasmódica, adstringente, dentre outras (Cunha, 2017).

Diante do exposto, este trabalho teve como objetivos produzir biofilmes de fécula de mandioca adicionados de extratos alcoólico e aquoso de própolis, determinar suas características físicas e mecânicas, bem como sua capacidade antibacteriana.

\section{Materiais e métodos}

A preparação dos filmes e caracterizações químicas foram realizadas no Laboratório de Processos Químicos, do Instituto Federal de São Paulo, Campus Suzano, em Suzano, Estado de São Paulo.

Os ensaios de propriedades mecânicas foram realizados no Laboratório Multiusuário, da Universidade Federal do ABC, campus Santo André, em Santo André, e no Laboratório de Qualidade da Empresa Suzano S.A., Unidade Rio Verde, no Município de Suzano, Estado de São Paulo.

Para a produção dos filmes, foi utilizado amido de mandioca comercializado como polvilho doce (Kisabor, Food Brands Indústria de Produtos Alimentícios S.A., Jundiaí, São Paulo, Brasil), adquirido na rede local de supermercados do Município de Suzano, Brasil. 0 plastificante utilizado foi o glicerol comercial da marca Dinâmica (São Paulo, Brasil). 0 extrato alcoólico de própolis da Mega Center essências, obtido na Região da Sé, São Paulo, Brasil. 0 extrato de própolis aquoso da Propomax, a partir da própolis verde (Apis Flora, Indústria Brasileira Ltda, Ribeirão Preto, Brasil), adquirido na rede farmacêutica do Município de Suzano, Estado de São Paulo.

\section{Preparação dos filmes}

Os filmes foram elaborados de acordo com a técnica de casting, proposta por Ferreira e Bento (2013). Para a solução filmogênica, utilizou-se amido a 3\% (m/v), glicerol a $0,8 \%$, em três concentrações $(1,2,1,5$ e 1,8\%) de extrato alcóolico de própolis (EGP) e de extrato aquoso de própolis (EAP).

Inicialmente, foram adicionados o amido e o glicerol à água deionizada, misturando-se o conteúdo em um béquer. Essa mistura foi aquecida, em banho-maria, a $70{ }^{\circ} \mathrm{C}$, sob agitação manual, até atingir a gelatinização do amido. Retirou-se do banho e aguardou-se o decaimento da temperatura até $50{ }^{\circ} \mathrm{C}$. Porcionou-se a mistura em seis béqueres e adicionaram-se a cada um deles os EAP e EGP nas concentrações desejadas.

Após a adição dos extratos, $30 \mathrm{~mL}$ das soluções foram transferidos para placas de Petri de vidro ( $90 \mathrm{~mm} \times 15 \mathrm{~mm}$ ), a fim de se obter espessuras padronizadas. As placas foram levadas à secagem em estufa (Solab, SL-100/150, $220 \mathrm{~V}$, Piracicaba, SP), a $55^{\circ} \mathrm{C}$ por aproximadamente $24 \mathrm{~h}$ ou até apresentarem aspecto seco.

Posteriormente, as placas foram colocadas em um dessecador contendo solução de cloreto de sódio supersaturada para facilitar a retirada dos filmes, por um período mínimo de $24 \mathrm{~h}$, os quais foram removidos com o auxílio de espátula e pinça.

\section{Caracterização dos filmes}

Análises subjetivas. As análises subjetivas dos filmes foram realizadas por meio de observações visuais, táteis e olfativas. Observaram-se propriedades como o aspecto da superfície, que deve ser homogênea e contínua, se havia fissuras, bolhas, ou partículas insolúveis e a cor dos mesmos.

Espessura. A espessura dos filmes foi determinada com micrômetro digital de bancada (Micrometer $51 \mathrm{L \& W}$ ) em cinco posições aleatórias para cada amostra, sendo realizada em triplicata para cada tipo de extrato e concentração. 
Densidade. A densidade foi determinada, em triplicata, a partir do método sugerido por Araújo (2014). Utilizaram-se corpos de prova de $9 \mathrm{~cm}^{2}$ dos filmes para cada concentração e tipo de extrato. Os corpos de prova de área conhecida foram desidratados em dessecador contendo sílica gel e pesados em balança semi-analítica (Marte/Shimadzu AY220 - 220 g x 0,001 g). Calculou-se a densidade por meio da Equação 1.

$$
d=\frac{m}{v}=\frac{m}{A x e}
$$
amostra.

Onde: $\mathrm{m}=$ massa da amostra (g); $\mathrm{A}=$ área da amostra $\left(9 \mathrm{~cm}^{2}\right)$ e "e" = espessura da

Gramatura. Para a medida da gramatura, utilizaram-se corpos de prova de $9 \mathrm{~cm}^{2}$ de área e, após a desidratação em dessecador contendo sílica gel, os corpos foram pesados em balança semi-analítica (Marte/Shimadzu AY220 - 220g x 0,001 g). Para o cálculo da gramatura, utilizou-se a massa da amostra medida, dividida pela área ocupada pela mesma (Henrique et al., 2008), conforme Equação 2.

$$
G=10000 \times \frac{m}{A}
$$

Onde: $\mathrm{G}=$ gramatura expressa por $\mathrm{g} / \mathrm{m}^{2}, \mathrm{~m}=$ massa da amostra $(\mathrm{g})$ e $\mathrm{a}=$ área da amostra $\left(\mathrm{cm}^{2}\right)$. As análises foram realizadas em triplicata.

Cor e opacidade. Determinaram-se a cor e opacidade com um espectrofotômetro da Lorentzen \& Wettre Elrepho, modelo 1200-0917 3000, de acordo com os padrões CIE Lab: com variações: $L^{*}$ de 0 (preto) a 100 (branco), a* do verde (-) ao vermelho $(+)$, e b* do azul (-) ao amarelo (+). Em amostras com diâmetro de $9 \mathrm{~cm}$, realizou-se o teste para cada concentração e tipo de extrato.

Determinação da aspereza Benstsen em bancada. Determinou-se a rugosidade dos biofilmes por meio do aparelho Bendtsen de bancada. Utilizaram-se os biofilmes em tamanho real (confeccionados em placas de Petri com diâmetro de $9 \mathrm{~cm}$ ), seguindo o procedimento operacional padrão do equipamento, com objetivo de determinar o grau de desuniformidade que a superfície do biofilme apresentava o teste foi realizado em triplicata para cada amostra.

Umidade, swelling e solubilidade. Para esta análise, utilizou-se o método sugerido por Pastor et al. (2012). Foram cortados corpos de prova do biofilme em quadrados de $9 \mathrm{~cm}^{2}$ e pesados em semi-analítica (Marte/Shimadzu AY220 - 220g x $0,001 \mathrm{~g}$ ), sendo esse peso descrito como massa 1 (M1). As amostras foram secas a $70^{\circ} \mathrm{C}$ por $24 \mathrm{~h}$ em uma estufa convencional (Solab, SL-100/150, 220 V, Piracicaba/SP), para se obter a massa seca inicial (M2). Após a pesagem, as amostras foram colocadas em uma placa de Petri contendo $30 \mathrm{~mL}$ de água destilada. 
As placas foram vedadas com Parafilm ${ }^{\mathrm{TM}}$ e deixadas em temperatura ambiente durante $24 \mathrm{~h}$. Após esse período, retiraram-se as amostras da água, secando-as superficialmente com papel filtro, e foram pesadas, obtendo o valor de massa 3 (M3). Em seguida, as amostras foram recolocadas na estufa, a $70{ }^{\circ} \mathrm{C}$ durante $24 \mathrm{~h}$, a fim de definir a massa seca final (M4). Foram realizados ensaios em triplicata. Os parâmetros obtidos foram utilizados para os cálculos através das Equações 3, 4 e 5.

$$
\begin{aligned}
& \text { Solubilidade }(\%)=\frac{(M 2-M 4)}{M 2} * 100 \\
& \text { umidade }(\%)=\frac{(M 1-M 2)}{M 1} * 100 \\
& \text { Swelling }(\%)=\frac{(M 3-M 2)}{M 2} * 100
\end{aligned}
$$

Onde: M1 = massa inicial da amostra; M2 = massa seca inicial; M3 = massa da amostra após contato com a água; M4 = massa seca final.

Propriedades mecânicas. Os ensaios de tração mecânica foram realizados no equipamento universal de ensaios mecânicos INSTRON 3369 (Grove City, USA). A coleta de dados deu-se por meio do software Bluehill.

Para realização dos ensaios utilizaram-se corpos de prova retangulares de $1,5 \mathrm{~cm} \mathrm{x}$ $6 \mathrm{~cm}$ (Figura 1), fixou-se o corpo na garra do dispositivo, com distância inicial de $30 \mathrm{~mm}$. Configurou-se o software do Bluehill com os dados necessários, e utilizou-se uma velocidade de $5 \mathrm{~mm} / \mathrm{min}$. Os ensaios foram realizados em triplicata para cada variação de extrato e consistiram na aplicação de tração no polímero até o momento da ruptura.

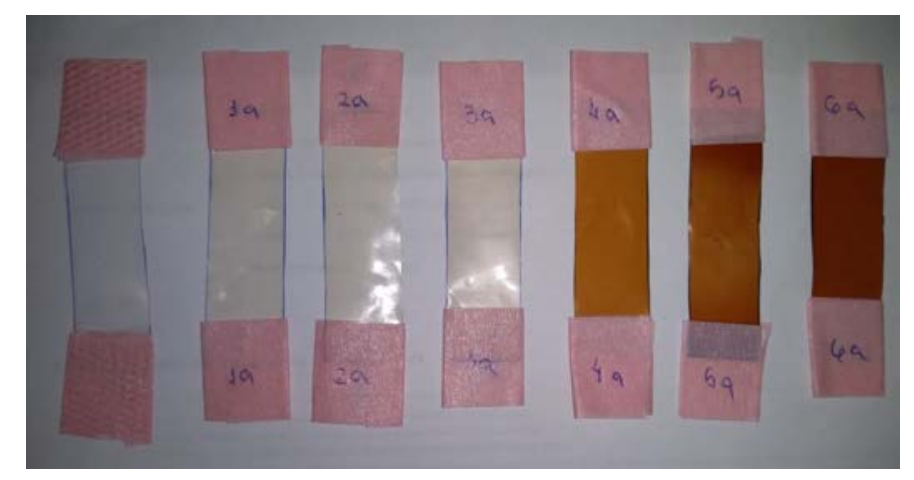

Figura 1. Corpos de prova (o primeiro à esquerda sem extratos, posteriormente com EEP 1,2\% $1,5 \%$ e $1,8 \%$, e os mais escuros com EAP 1,2\%, 1,5\% e 1,8\%,).

Resistência máxima à tração (MPa). Representada pela Equação 6 em que a (Rmáx) é dada pela relação da força máxima aplicada ao corpo de prova (Fmáx) sobre a área do corpo de prova $(\mathrm{A})$. 


$$
R_{\text {máx }}=\frac{F_{\text {máx }}}{A}=\frac{F_{\text {máx }}}{e \cdot L_{i}}
$$

Onde: Rmáx $=$ resistência máxima à tração; Fmáx = força máxima; $A$ = área do corpo de prova.

Alongamento na Ruptura (\%). A elongação na ruptura dos filmes (E), determinou-se pela Equação 7, sendo esta a relação percentual entre a elongação do corpo de prova no momento de ruptura (Erup) e a distância entre as garras no momento inicial do teste (Dgarras).

$$
E=\frac{E_{\text {rup }}}{D_{\text {garras }}} \times 100
$$

As propriedades foram determinadas por meio de curvas de tensão de formação, estimadas a partir de dados obtidos durante o ensaio.

Determinação de resistência ao rasgo em bancada. A determinação de resistência ao rasgo foi realizada seguindo o procedimento operacional padrão (com ajustes) para o equipamento "Tear Tester SE-009", da Lorentzen \& Wettre. Os corpos de prova foram cortados nas dimensões: $63 \mathrm{~mm}$ largura por $53 \mathrm{~mm}$ de comprimento em uma guilhotina padrão (sample punch) e colocados no suporte das garras, com o menor lado na direção horizontal, e realizou-se o teste, de acordo com método preconizado por Suzano Papel e Celulose (2019a).

Permeabilidade ao vapor de água. Determinou-se a permeabilidade ao vapor de água (PVA) segundo o método ASTM E96-95 (Bodini, 2011), com adaptações, para todas as amostras dos filmes produzidos e também com um saco de embalagem transparente 100\% PEBD (polietileno de alta densidade) e com filme de PVC (policloreto de polivinila) transparente. Utilizaram-se círculos com diâmetro de $90 \mathrm{~mm}$ para cada amostra, previamente mantidas em dessecador por $48 \mathrm{~h}$. As amostras foram fixadas com fita crepe em potes de vidro pequenos contendo sílica gel, com massa conhecida, deixando uma área exposta de $30 \mathrm{~mm}$; o restante foi vedado com Parafilm ${ }^{\mathrm{TM}}$, as amostras foram acondicionadas, juntamente com um béquer contendo água destilada, em dessecador vedado com Parafilm ${ }^{\mathrm{TM}}$, onde permaneceram por sete dias.

Cinzas. A porcentagem de cinzas foi obtida de acordo com o procedimento operacional padrão da Empresa Suzano S.A., com adaptações. As amostras com área de $9 \mathrm{~cm}^{2}$ de massa conhecida (MI), foram colocadas em cadinhos de porcelanas previamente pesados (MC) e colocadas em mufla por aproximadamente $1 \mathrm{~h}$ a $500^{\circ} \mathrm{C}$, ou até quando não houvesse partículas escuras derivadas de matéria orgânica. Retirou-se o cadinho da mufla, esperou-se resfriar e pesou-se para obter a massa de cinzas (MF) presente nos filmes, de acordo com o cálculo representado na Equação 8 (Suzano Papel e Celulose, 2019b). 


$$
\% C \arg a=\frac{(M F-M C)}{(M I-M C)} * 100
$$

Onde: $\mathrm{MI}=$ massa inicial da amostra; $\mathrm{MC}=$ massa do cadinho; $\mathrm{MF}=$ massa da amostra após incineração.

Estudo da biodegradabilidade dos filmes. 0 estudo foi realizado nas dependências do Instituto Federal de São Paulo (IFSP), Campus Suzano, segundo a técnica sugerida por Gomes (2008), com adaptações. Perfuraram-se no solo, caracterizado como arenoso de densidade $1,32 \mathrm{~g} / \mathrm{cm}^{3}$ (Nagaishi, 2018), dois retângulos com área de aproximadamente $140 \mathrm{~cm}^{2}$ cada e profundidade de $30 \mathrm{~cm}$. Colocaram-se vasos no interior da área perfurada com o intuito de delimitá-la e em seguida as amostras dos filmes com diâmetro $9 \mathrm{~cm}$, espessura média $0,015 \mathrm{~cm}$ e gramatura média de $20 \mathrm{~g} / \mathrm{cm}^{2}$, foram marcadas para diferenciar a concentração e tipo de extrato, e enterradas por aproximadamente 45 dias. As etapas são ilustradas na Figura 2.

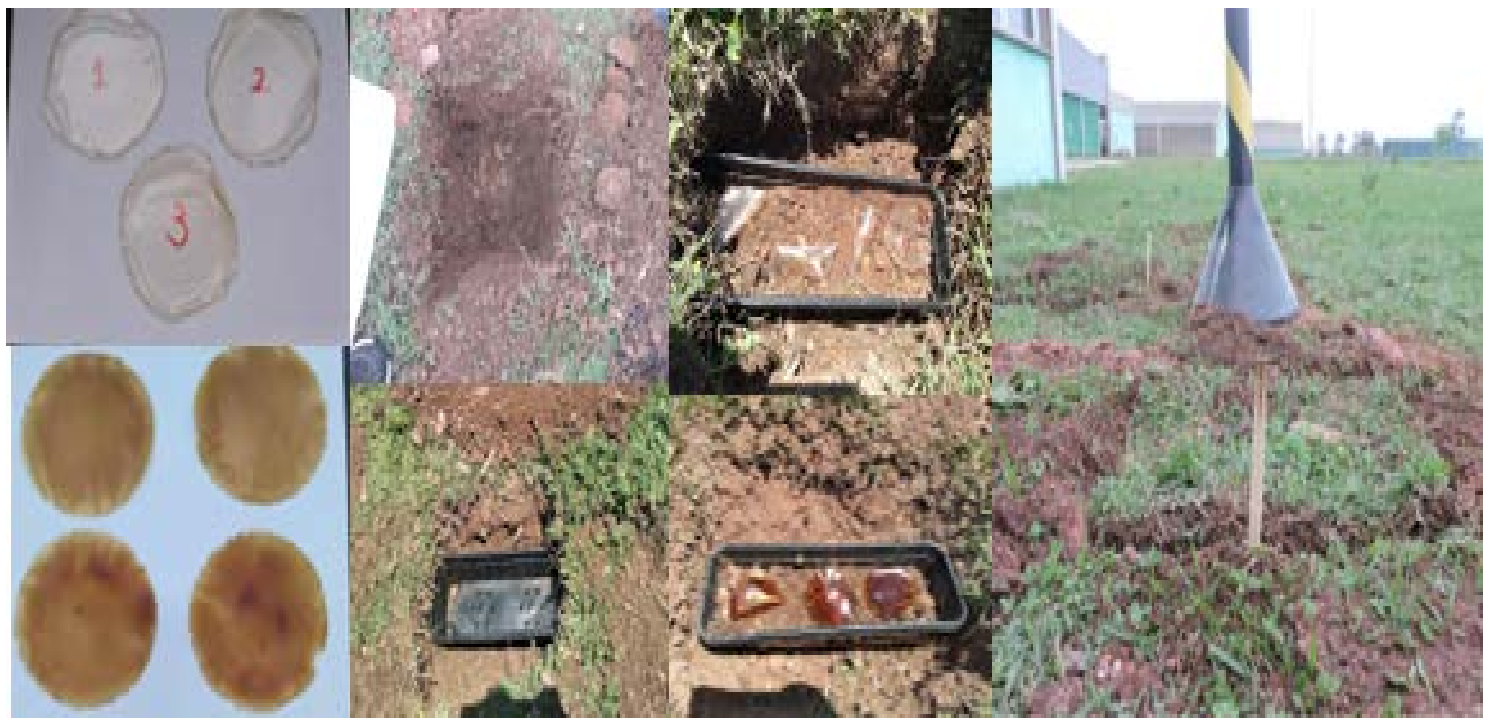

Figura 2. Ilustração das etapas realizadas no estudo da biodegradabilidade dos filmes.

Preparo das suspensões das cepas bacterianas. As cepas de Escherichia coli (ATCC 11229) e Staphylococcus aureus (ATCC 25923) foram reativadas, transferindo-se assepticamente uma alçada de cada uma das culturas para tubos de caldo triptona de soja (TSB), seguidos de incubação a $35^{\circ} \mathrm{C}$ por $24 \mathrm{~h}$. As culturas bacterianas reativadas foram inicialmente diluídas até $1,5 \times 10^{-8} \mathrm{UFC} / \mathrm{mL}$ (correspondente ao padrão 0,5 da escala McFarland), empregando-se solução salina a 0,85\% como diluente. A partir desta diluição, realizaram-se diluições seriadas, de maneira a se obter suspensões com as concentrações de $10 \mathrm{UFC} / \mathrm{mL}, 100 \mathrm{UFC} / \mathrm{mL}, 1.000 \mathrm{UFC} / \mathrm{mL}$ e $10.000 \mathrm{UFC} / \mathrm{mL}$ (CLSI, 2006).

Avaliação da atividade antibacteriana dos extratos de própolis. Em tubos de ensaio estéreis adicionaram-se $48 \mu \mathrm{L}, 60 \mu \mathrm{L}$ e $72 \mu \mathrm{L}$ dos extratos alcoólico e aquoso de própolis, 2,0 mL de cada uma das diluições das suspensões bacterianas supracitadas, avolumando-se para $4 \mathrm{~mL}$ com meio TSB, a fim de se obter as concentrações de extratos 
iguais a $1,2 \%, 1,5 \%$ e $1,8 \%$, respectivamente. Todos os tubos foram incubados a $35^{\circ} \mathrm{C}$ por 48 h. Após incubação, uma alçada de cada amostra foi estriada na superfície de ágar triptona de soja (TSA), com incubação a $35{ }^{\circ} \mathrm{C}$ por $48 \mathrm{~h}$ para posterior verificação da ausência ou presença de crescimento bacteriano. Esses testes foram realizados em triplicata.

\section{Resultados e discussão}

\section{Análises subjetivas}

Os filmes de amido de mandioca plastificados com glicerol (controle) considerados satisfatórios foram os que se apresentaram transparentes, homogêneos, com boa manuseabilidade, sem a presença de fissuras ou craqueamento e bolhas na superfície. Os filmes adicionados de extrato alcoólico de própolis (EGP) tornaram-se amarelados, enquanto que os adicionados de extrato aquoso de própolis (EAP) ficaram marrons (Figura 3). Os filmes também apresentaram um odor residual característico da própolis, sendo que nos produzidos com EAP esse aroma teve maior prevalência.

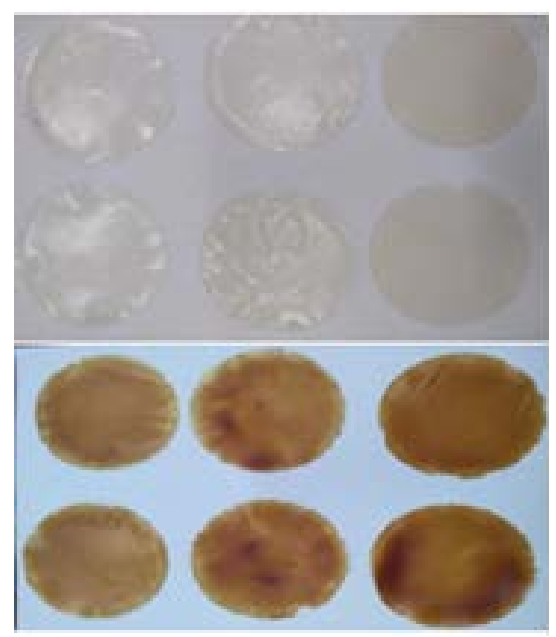

Figura 3. Filmes de amido de mandioca com EGP (acima) e EAP (abaixo).

\section{Espessura, gramatura e densidade}

A técnica de casting utilizada no desenvolvimento dos filmes, juntamente com o uso de proveta de plástico para a distribuição de volumes fixos em placas de Petri, permitiu um controle satisfatório da espessura pelo método de secagem utilizado, a diferença média entre esses valores deu-se principalmente pela variação e tipo de extrato usado e por conta de desníveis de secagem da estufa, pois a mesma não apresentava circulação de ar adequada, impedindo a secagem homogênea dos filmes.

Os menores valores de espessura e gramatura foram observados para a amostra controle $\left(137 \pm 8 \mu \mathrm{m}\right.$ e $19,56 \pm 0,24 \mathrm{~g} / \mathrm{cm}^{2}$, respectivamente), enquanto as amostras EAP apresentaram os maiores valores de espessura (entre $153 \pm 10$ e $160 \pm 6 \mu \mathrm{m}$ ) e de gramatura $\left(21,59 \pm 0,91\right.$ e $\left.25,30 \pm 0,64 \mathrm{~g} / \mathrm{cm}^{2}\right)$.

Assim como a espessura, a gramatura está diretamente ligada à resistência mecânica do material (Henrique et al., 2008). Observou-se que as variações da gramatura ocorreram de acordo com o aumento de volume dos extratos se comparado com o controle, o que pode implicar em uma maior resistência mecânica dos filmes, comprovada 
com o ensaio de tração, mas também pode estar relacionado com a variação de espessura já relatada anteriormente.

Os filmes de amido apresentaram valores de densidade bem próximos entre si, com variações que poderiam estar relacionadas com a espessura, uma vez que houve variações já discutidas, indicando que a adição de extrato não interferiu nessa propriedade. Os resultados obtidos foram bem próximos ao relatado por Araújo (2014) para filmes com concentração de amido de $3 \mathrm{~g}$ de amido/100 g de solução filmogênica, $20 \mathrm{~g}$ de glicerol $/ 100 \mathrm{~g}$ de amido e extrato alcóolico de própolis $(0,5 \%, 0,75 \%$ e 1\%) em relação à solução filmogênica total.

\section{Cor e opacidade}

Segundo Luchese (2018), a coordenada $L^{*}$ é uma medida de luminosidade, onde os valores variam de 0 (preto) a 100 (branco). A coordenada de cromaticidade $a^{*}$ pode assumir valores negativos (verde) e valores positivos (vermelha), já a cromaticidade b* varia de valores negativos (azul) a positivos (amarela).

A incorporação de extrato de própolis tanto EGP quanto EAP influenciou nas variações das características dos filmes. Segundo Pastor (2012), essa mudança é causada, pois a adição de extrato na matriz promove maior dispersão da luz, causando um índice de refração diferente do que se a matriz fosse homogênea.

Comparando-se com o controle, onde $\mathrm{L}^{*}$ tende ao Branco $(68,06)$, a* ao verde $(-$ $0,95)$ e $b^{*}$ ao azul $(-0,23)$, ao adicionar EGP, o $L^{*}$ tende a diminuir (variando entre $61,16 \mathrm{e}$ $63,23)$, mas ainda tendendo ao branco, os valores de $a^{*}$ e de $b^{*}$ tornam-se positivos, tendendo ao vermelho (entre 0,03 e 0,83 ) e ao amarelo $(11,93$ e 16,5), respectivamente, a opacidade aumentou (variando entre 3,8 e 6,78). Nos filmes EAP, os valores de $L^{*}$ decaíram mais do que a metade, se comparado com o controle (entre 18,41 e 21,63), a* passou a tender ainda mais para o vermelho $\left(14,78\right.$ a 16,69) e $b^{*}$ continuou tendendo para o amarelo $(12,84)$, porém, com o aumento da concentração, essa tendência diminuiu $(7,51)$; já a opacidade aumentou drasticamente (entre 44,3 e 65,15), isso se dá porque o EAP deixa o filme com uma coloração bem escura.

\section{Aspereza Benstsen}

A aspereza ou rugosidade dos filmes teve como objetivo mostrar o grau de desuniformidade da superfície do biofilme. Os resultados obtidos variaram entre 0 e 3 , considerados satisfatórios, por estarem próximos de zero, o que mostrou que tanto a superfície em contato direto com a placa de vidro quanto a superior, em contato direto com o ar quente, ficaram bem uniformes, "lisas", característica que é esperada em filmes deste tipo

\section{Swelling, solubilidade e umidade}

Em testes realizados por Luchese (2018), o conteúdo de umidade observado para filmes de amido de mandioca e glicerol foram, em média, $24 \%$, valor acima do encontrado no presente trabalho, podendo ressaltar que com adição de EGP, os percentuais de umidade $(14,43 \pm 0,34$ a $15,19 \pm 3,23)$ foram similares aos teores de umidade do filme controle $(14,01 \pm 0,37)$, destacando os filmes com EAP, onde esses valores foram maiores $(16,74 \pm 0,75$ a 17,81 $\pm 1,0)$, aproximando-se do encontrado na literatura citada, indicando que o tipo de extrato influencia o teor de umidade do filme e sua solubilidade, onde valores obtidos foram, controle $(12,34 \pm 1,13)$, EGP $(12,28 \pm 0,37$ a $15,87 \pm 0,57)$ e EAP $(19,41 \pm 0,34$ a $23,49 \pm 0,99)$, sendo capaz de alterar sua higroscopicidade.

Portanto, os valores de umidade e solubilidade, apesar das diferenças obtidas para cada tipo de extrato, apresentaram resultados satisfatórios, mas deve-se ressaltar que o filme com EAP foi o menos eficiente, com maior porcentagem de umidade e solubilidade, uma vez que para embalagens, essas características não são adequadas. Todavia, foram 
bem próximos e até mais eficientes do que os parâmetros encontrados na literatura disponível.

Segundo Pires (2017), o swelling indica o quanto de água o filme é capaz de absorver, que por sua vez é transmitida para o interior do produto. 0 conhecimento deste parâmetro é importante para prever a qualidade e o desempenho dos materiais de embalagens durante o armazenamento de produtos nelas acondicionados. Em geral, com a incorporação dos extratos houve uma diminuição da porcentagem de swelling, sendo que esta diminuição foi mais visível para EAP $(99,69 \pm 1,42$ a 103,61 $\pm 4,89)$ do que no EGP $(108,88 \pm 8,08$ a 159,03$)$ se comparado com o filme controle $(141,05 \pm 12,46)$. Isso se dá, pois, à incorporação de extrato nos filmes diminui a sua afinidade com a água, tornando estes mais hidrofóbicos.

\section{Propriedades mecânicas}

Os ensaios de propriedades mecânicas dos filmes controle, EGP e EAP, relacionados aos parâmetros de Resistência à tração $\left(R_{\max }\right)$, Elongação na ruptura (E) objetivam determinar a resistência mecânica ou tensão máxima que o filme suporta antes de se romper, uma vez que a sua produção tem um foco significativo na área de embalagens, e devem ser resistentes às tensões externas de modo a se manterem íntegras no período de sua utilização.

Observou-se que $R_{\text {MÁx }}$ do filme EGP a 1,2 \% foi inferior $(2,13 \pm 0,13)$ ao obtido para o controle $(2,25 \pm 0,16)$, porém com o aumento da concentração de EGP, essa resistência aumentou $(2,38 \pm 0,16-2,84 \pm 0,11)$. Já nas amostras com adição de EAP, a com menor concentração apresentou maior resistência e esta decaiu com o aumento da concentração de extrato de própolis aquoso $(2,48 \pm 0,09-2,26 \pm 0.10)$.

No ensaio de elongação na ruptura (E), o filme controle obteve o valor de 58,62 \pm 9,33, enquanto os filmes com adição de EGP apresentaram valor médio de 66,21 \pm 9,98 e EAP $56,85 \pm 3,52$. Estes resultados mostraram que os filmes com adição de EAP tornaramse menos resistentes, enquanto os com EGP, mais resistentes, indicando que a composição química do extrato influenciou nas propriedades mecânicas dos filmes.

\section{Determinação de resistência ao rasgo em bancada}

Os testes de resistência ao rasgo dos filmes controle e com diferentes concentrações de EGP e EAP tiveram resultados satisfatórios e indicaram que a incorporação dos extratos resultou em filmes com maior resistência ao rasgo em comparação ao filme controle $(16 \pm 1,25 \mathrm{~g} / \mathrm{f})$, variando de $18 \mathrm{~g} / \mathrm{f} \pm 1,63$ a $23 \mathrm{~g} / \mathrm{f} \pm 2,83$, sendo que o extrato aquoso se destacou por conferir maior resistência aos filmes.

\section{Permeabilidade ao vapor de água}

Os valores de permeabilidade ao vapor de água para os filmes de amido com glicerol sem extrato (controle) e com adição de EGP e EAP não apresentaram diferenças significativas, os quais variaram entre $14 \%$ e $15 \%$ de absorção. 0 saco $100 \%$ PEBD (polietileno de alta densidade) teve apenas 1\% e o filme de PVC (policloreto de polivinila) 5\% de absorção, mostrando que, apesar de a porcentagem de absorção dos filmes de amido ser maior, ainda assim é baixa, mostrando que todos foram eficientes no bloqueio de umidade.

\section{Cinzas (\%)}

Não foram encontrados na literatura valores de porcentagem de resíduos inorgânicos em filmes à base amido para se estabelecer comparação com os filmes à base de fécula de mandioca produzidos neste trabalho. Assim, compararam-se os valores da amostra controle $(0,25 \pm 0,04)$ com os dos filmes incorporados com extratos. Observou-se um aumento de carga significativa (variando de $0,35 \pm 0,02 \%$ a $0,55 \pm 0,09$ com o aumento 
da concentração e porcentagem do extrato), indicando que os extratos contribuíram para o aumento da carga nos filmes, sugerindo que em sua composição há matéria inorgânica.

\section{Biodegradabilidade}

A biodegradabilidade dos filmes sem extrato e com EGP e EAP foi investigada por meio de um experimento em solo de características previamente conhecidas (Figura 4). Eles foram expostos à ação de microrganismos presentes naturalmente em solo orgânico durante 45 dias. Após esse período, todos os filmes foram totalmente degradados em condições ambientais naturais. Com os resultados obtidos, é possível afirmar que os componentes dos polímeros serviram como fonte de energia (ou ação de enzimas) para os microrganismos naturalmente presentes no solo.

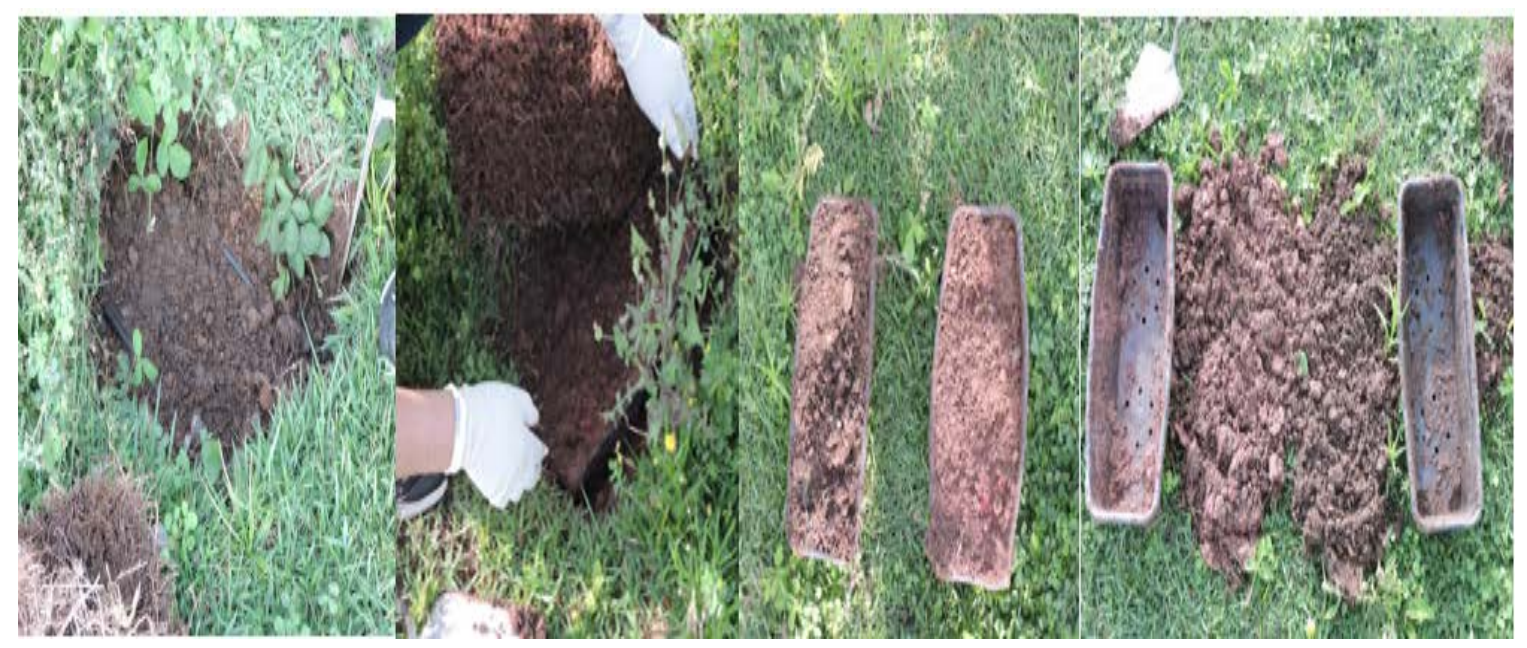

Figura 4. Área onde foram enterrados os filmes, após o período de teste.

\section{Avaliação da atividade antibacteriana dos extratos de própolis}

Não se observou crescimento bacteriano nas placas de TSA onde estrias de amostras de extratos alcoólico e aquoso de própolis foram semeadas após $48 \mathrm{~h}$ de contato com as suspensões bacterianas de $E$. coli e $S$. aureus contendo 10, 100, 1.000 e 10.000 $\mathrm{UFC} / \mathrm{mL}$, fato que permite afirmar que os referidos extratos nas três concentrações estudadas $(1,2 \%, 1,5 \%$ e 1,8\%) apresentaram atividade contra as bactérias.

\section{Conclusões}

Os biofilmes foram produzidos satisfatoriamente a partir da técnica de casting, utilizando a fécula de mandioca e o glicerol como plastificante (controle), resultando em amostras transparentes, homogêneas, maleáveis e sem bolhas ou fissuras. A adição dos extratos de própolis causou alteração nas cores dos filmes, sendo mais amarelado com o extrato alcóolico e mais marrom com o extrato aquoso. Detectou-se também a existência de um odor residual nos filmes proveniente da própolis.

As espessuras dos filmes foram controladas de modo satisfatório, levando-se em consideração o método que foi utilizado. Notou-se que as diferenças ocorreram principalmente devido à secagem desigual na estufa e pela variação nos extratos. Já para a gramatura, constatou-se que as variações aconteciam de acordo com o aumento no volume 
dos extratos, e que para a densidade, a adição dos extratos não interferiu nos resultados encontrados.

A incorporação dos extratos de própolis às amostras também influenciou diretamente a opacidade dos biofilmes, fazendo com que os valores aumentassem em relação ao controle. Quanto à aspereza, o teste demonstrou uniformidade nas superfícies, o que é ideal para esse tipo de material.

Para as propriedades mecânicas, observou-se que as maiores concentrações de EGP resultaram em um aumento da resistência. Contudo, para o EAP, a situação foi inversa. Já para o teste de resistência ao rasgo, o filme com extrato aquoso de própolis se destacou por apresentar maior resistência.

Em relação ao teor de umidade e solubilidade dos biofilmes, percebeu-se que o tipo de extrato influencia diretamente nesses valores, sendo capaz de alterar sua higroscopicidade. Quanto ao ensaio de swelling, a presença do extrato diminui a afinidade dos filmes com a água, tornando estes mais hidrofóbicos, reduzindo o grau de intumescimento.

Para os valores de permeabilidade ao vapor de água dos filmes, as amostras controle e com adição de EGP e EAP não apresentaram diferenças significativas, ficando entre $14 \%$ e 15\%. Embora as porcentagens obtidas sejam maiores em comparação ao saco PEBD e ao filme de PVC, os valores ainda são baixos, confirmando a eficiência dos filmes produzidos.

Quanto à análise de cinzas, observou-se um aumento de carga significativa, indicando que os extratos contribuíram para o aumento da matéria inorgânica nestes materiais.

O ensaio de biodegradabilidade demonstrou completa degradação dos biofilmes após o período de 45 dias em condições ambientais naturais. Logo, é possível afirmar que os componentes dos polímeros serviram como fonte de energia para os microrganismos naturalmente presentes no solo.

Os extratos alcóolico e aquoso de própolis nas três concentrações estudadas $(1,2 \%$, $1,5 \%$ e $1,8 \%$ ) exibiram atividade contra $E$. coli e $S$. aureus.

Pode-se constatar que os biofilmes de fécula de mandioca, adicionados do composto ativo extrato de própolis, têm grande potencial para serem utilizados como possível alternativa aos polímeros sintéticos no desenvolvimento de embalagens, ainda mais, se aliados a outros ensaios de caracterização físico-química e ao refinamento e otimização dos meios de produção.

\section{Agradecimentos}

Ao técnico de Laboratório da Universidade Federal do ABC, Sr. Arnaldo Soares Filho, por auxiliar nos ensaios mecânicos.

\section{Conflito de interesses}

As autoras declaram não haver conflito de interesses.

\section{Referências}

Alves, G. S.; Sampaio, A. P. L.; Zavolski, C. A.; Brito, V. H.; Cereda, M. P.; Neves, E. Material à base de amido de mandioca para manufatura de embalagem de alimentos. Revista Citino, v. 2, n. 1, p. 16-24, 2012. 
Araujo, G. K. P. Desenvolvimento de filmes biodegradáveis de amido incorporados com extrato de própolis. Campo Mourão: Universidade Tecnológica Federal do Paraná, 2014. (TCC de graduação).

Bodini, R. B. Desenvolvimento de materiais poliméricos bioativos à base de gelatina e própolis. Pirassununga: Universidade São Paulo, 2011. (Tese de doutorado).

Brito, G. F.; Agrawal, P.; Araújo, E. M.; Mélo, T. J. A. Biopolímeros, polímeros biodegradáveis e polímeros verdes. Revista Eletrônica de Materiais e Processos, v. 6, n. 2, p. 127-139, 2011.

CLSI - Clinical and Laboratory Standards Institute. Methods for dilution antimicrobial susceptibility tests for bacteria that grow aerobically: Approved standards. 6. ed. Wayne, PA: Clinical and Laboratory Standards Institute, 2006.

Cunha, G. F. Biofilmes à base de amido incorporados com extrato etanólico de própolis. Rio Verde: Instituto Federal de Educação, Ciência e Tecnologia Goiano, 2017. (TCC de graduação).

Da Róz, A. L. Preparação e caracterização de amidos termoplásticos. São Carlos: Universidade de São Paulo, 2004. (Tese de doutorado).

Ferreira, B. M.; Bento, H. B. S. Produção e análise de um biopolímero a partir de fécula de mandioca com adição de glicerol. Lorena: Universidade de São Paulo, 2013. (TCC de graduação).

Garcia, A. P. Desenvolvimento de filmes biodegradáveis ativos à base de amido de milho adicionados de extrato de própolis. Campo Mourão: Universidade Tecnológica Federal do Paraná, 2016. (TCC de graduação).

Gomes, A. M. M. Preparação, caracterização e avaliação da biodegradabilidade de blendas de amido/quitosana/PVA. Fortaleza: Universidade Federal do Ceará, 2008. (Tese de doutorado).

Henrique, C. M.; Cereda, M. P.; Sarmento, S. B. S. Características físicas de filmes biodegradáveis produzidos a partir de amidos modificados de mandioca. Ciência e Tecnologia de Alimentos, v. 1, n. 28, p. 231-240, 2008.

IBGE - Instituto Brasileiro de Geografia e Estatística. Pesquisa mensal de previsão e acompanhamento das safras agrícolas no ano civil - estatística da produção agrícola. 2018. Disponível em: <https://agenciadenoticias.ibge.gov.br/media/com_mediaibge/arquivos/ eaeb7bd3a7d0941cfb93ace38dc13f86.pdf>. Acesso em: 24 ago. 2020.

Larotonda, F. D. S. Desenvolvimento de biofilmes a partir da fécula de mandioca. Florianópolis: Universidade Federal de Santa Catarina, 2002. (Dissertação de mestrado).

Luchese, C. L. Desenvolvimento de embalagens biodegradáveis a partir de amido contendo subprodutos provenientes do processamento de alimentos. Porto Alegre: Universidade Federal do Rio Grande do Sul, 2018. (Tese de doutorado).

Nagaishi, D. T. Estudo da aplicação do hidrogel reutilizado de fraldas descartáveis em solo arenoso. Suzano: IFSP, 2018 (Relatório de iniciação científica). 
Pastor, C.; Sánchez-González, L.; Chiralt, A.; Cháfer, M.; González-Martínez, C. Physical and antioxidant properties of chitosan and methylcellulose based films containing resveratrol, Food Hydrocolloids, v. 30, n. 1, p. 272-280, 2012. https://doi.org/10.1016/ j.foodhyd.2012.05.026

Petrikoski, A. P. Elaboração de biofilmes de fécula de mandioca e avaliação do seu uso na imobilização de caulinita intercalada com ureia. Pato Branco: Universidade Tecnológica Federal do Paraná, 2013. (Dissertação de mestrado).

Pires, J. R. A. Desenvolvimento de biofilmes para a indústria alimentar. Lisboa: Universidade Nova de Lisboa, 2017. (Dissertação de mestrado).

Schlemmer, D. Preparação, caracterização e degradação de blendas de poliestireno e amido termoplásticos usando glicerol e óleo de buriti (Mauritia flexuosa) como plastificantes. Brasília: Universidade de Brasília, 2007. (Dissertação de mestrado).

Silva, B. B.; Mendes, F. B. G.; Kageyama, P. Y. Mandioca. Piracicaba: Universidade de São Paulo, Escola Superior de Agricultura "Luiz de Queiroz", 2008. (Projeto desenvolvimento econômico-social).

Silva, J. R.; Moritz, D. L.; Santos, E. T.; Fagundes, A. B.; Beuren, F. H. Polímeros biodegradáveis e biopolímeros: uma opção de produção mais limpa para embalagens alimentícias de origem fóssil. Anais do VII Congresso Brasileiro de Engenharia de Produção, Paraná, 2017.

Suzano Papel e Celulose. Elaboração do procedimento operacional padrão para determinação de resistência ao rasgo em bancada para o laboratório de papel. Suzano: Suzano, Papel e Celulose, 2019a.

Suzano Papel e Celulose. Elaboração do procedimento operacional padrão para determinação de porcentagem de cargas em mufla e ou incinerador. Suzano: Suzano, Papel e Celulose, 2019b.

Informação da Licença: Este é um artigo Open Access distribuído sob os termos da Licença Creative Commons Attribution, que permite uso irrestrito, distribuição e reprodução em qualquer meio, desde que a obra original seja devidamente citada. 